\title{
O CONCEITO DE DIALÉTICA EM LUKÁCS
}

\author{
MÉSZÁROS, István. \\ O conceito de dialética em Lukács. \\ São Paulo: Boitempo, 2013, 174 p.
}

POR

Ronaldo Gaspar ${ }^{l}$

ão raros os homens que viveram o suficiente para dedicar quase setenta anos de sua existência à atividade intelectual - sobretudo se esta tiver sido notoriamente intensa, profunda e profícua. E ainda mais raros são aqueles que, nessa trajetória, foram capazes de, por seu rigoroso compromisso com a busca pela verdade filosófica e científica, manter elevado o espírito da autocrítica e, com ele, um invejável desprendimento em relação aos seus resultados. György Lukács foi um desses homens.

Em sua longa vida, Lukács produziu obras de grande qualidade. Dentre elas, há aquelas que, à revelia das concordâncias ou discordâncias do próprio filósofo, influenciaram gerações de pensadores e se constituíram em referências para tendências de pensamento internas ou externas ao marxismo. Há também outras, que, por sua amplitude e sistematicidade, constituem exemplos praticamente únicos no pensamento marxista - sobre estética e ontologia. De qualquer modo, História e consciência de classe (LUKÁCS, 2003) ainda é sua obra mais conhecida. Nem todos sabem, porém, que, antes e depois desse livro tão influente, o pensamento de Lukács passou por mudanças importantes, as

\footnotetext{
${ }^{1}$ Professor Adjunto do Departamento de Ciências Sociais, Centro de Letras e Ciências Humanas, da Universidade Estadual de Londrina (UEL). Brasil. ronaldogaspar@uel.br
} 
quais se irradiaram por todos os campos do conhecimento pelos quais ele se aventurou - estética, história da filosofia, epistemologia, ontologia, política etc. Investigar, rastrear e compreender essas mudanças não é uma tarefa fácil, tanto pela extensão quanto pela complexidade e abrangência de suas reflexões. Mas, se não é fácil, é necessária. Isso porque, ao tomar seus trabalhos escritos até 0 início dos anos 1920 como expressão adequada de sua obra, o desavisado leitor pode extrair conclusões inconsistentes em relação aos posicionamentos/ideias avalizados por Lukács em trabalhos da maturidade, nos quais as ideias daqueles foram, muitas vezes, ulteriormente explicadas e/ou, sem nostalgia, abandonadas ou superadas.

Consoante, então, à necessidade de indicar algumas continuidades e descontinuidades da complexa trajetória intelectual de Lukács, a editora Boitempo, que já conta em seu catálogo com as importantíssimas "grande" e "pequena" ontologia (Para ontologia do ser social e Prolegômenos para uma ontologia do ser social), publicou recentemente um pequeno livro, escrito há mais de 40 anos por István Mészáros - um dos mais conhecidos discípulos de Lukács e, para alguns, o maior filósofo marxista vivo -, que auxilia a rastreá-las: $O$ conceito de dialética em Lukács. Nele, Mészáros analisa algumas das mudanças ocorridas no pensamento do velho mestre.

Embora apresentado pelo autor com modéstia, o livro de Mészáros tem muitos méritos. Dentre os quais, sem incorrer em determinismos ou reducionismos sociológicos, é notável sua exposição e avaliação de como as inflexões no pensamento de Lukács não ocorrem somente em relação ao desenvolvimento interno das ideias - sejam as de outros ou, então, do próprio filósofo -, mas também no contexto das transformações, impasses e desdobramentos do processo histórico. Quanto a este, inclusive, é muito esclarecedor seu tratamento das específicas condições de Lukács no âmbito das transformações mais abrangentes, pois o evolver de suas ideias foi bastante afetado pelo silenciamento político imposto pelo estalinismo e pela encruzilhada do vazio de instituições políticas de mediação para o avanço do socialismo na URSS.

Como aspecto central de sua reflexão, Mészáros privilegia o conceito de dialética, pois, como ele mesmo pontua em seu livro, "os problemas da dialética ocupam um lugar central no pensamento de Lukács" (MÉSZÁROS, 2013, p. 29). E, de fato, em seu livro o autor demonstra como, num movimento contínuodescontínuo, esses problemas foram enfrentados por Lukács de modo quase obsessivo, especialmente aqueles relativos à totalidade e à mediação, tendo em 
vista que ambos são essenciais em qualquer tentativa séria de resolução de uma questão fundamental do ser social: a relação entre ser (Sein) e dever-ser (Sollen). Com isso, evidencia como, de seus escritos idealistas da juventude às "ontologias" dos últimos anos de sua vida, dos explosivos ensaios de cunho românticorevolucionário à sistemática obra da maturidade, o tratamento dessa relação ocupa um papel destacado no pensamento do marxista húngaro. $\mathrm{E}$, também, como a vinculação ao idealismo e a ausência de possibilidades concretas decorrentes da sufocante atmosfera sociopolítica húngara - "na qual a interação das contradições heterogêneas [...] tendia a emascular todas as forças do dinamismo social, mantendo-as presas à sufocante imobilidade conservadora" (MÉSZÁROS, 2013, p. 36) - fizeram com que Lukács, bastante impactado pelo caráter democrático-revolucionário da poesia do jovem Endre Ady, escrevesse seus próprios textos de juventude sob a forma de ensaios. Neles, suas tentativas, bastante originais e instigantes, mas não necessariamente bem sucedidas, de resolução de problemas da dialética, como a totalidade e a mediação, exploraram ao limite essa forma de exposição textual.

0 autor ainda explora como a própria noção de dialética de Lukács é impactada pelo contexto político e histórico: "suas perspectivas mudaram no decorrer dos levantes sociais de 1917-1918” (MÉSZÁROS, 2013, p. 37). A partir daí, com sua crescente vinculação ao marxismo, a prosa filosófico-científica teve que substituir o ensaio como forma de exposição de suas ideias - para Mészáros, A teoria do romance é a sua última grande expressão -, mas "o confronto original com o 'Sollen', com o dever-ser, continuou sendo uma dimensão estruturadora fundamental de todo o pensamento de Lukács" (MÉSZÁROS, 2013, p. 39). Um confronto alimentado por seu crescente "desejo de objetividade" (MÉSZÁROS, 2013, p. 45), cuja culminação são seus trabalhos sobre ontologia.

0 primeiro grande trabalho desse novo período e, a mesmo tempo, a principal e mais influente em sua transição ao marxismo foi História $e$ consciência de classe. Mészáros salienta que foi nesse trabalho que Lukács "conseguiu, pela primeira vez, levantar a questão da 'totalidade concreta' ao mais alto nível de generalização" (MÉSZÁROS, 2013, p. 57), desenvolvendo-a em "Moses Hess e os problemas da dialética idealista" (LUKÁCS, ${ }^{2005)}$, 0 jovem Hegel (LUKÁCS' 1963) Introdução a uma estética marxista (LUKÁCS, 1970) dentre outros trabalhos. Ou seja, ele finalmente compreendeu que, mais do que qualquer postulado moral ou filosófico, é a economia o fundamento concreto da categoria totalidade no ser social. Por isso, como desdobramento filosófico-científico, asseverou que "a crítica da economia política não é mais uma ciência ao lado de 
outras, não é apenas colocada sobre as outras como uma 'ciência básica'; antes, ela abarca todo o mundo da história das 'formas da existência' (as categorias) da sociedade humana" (LUKÁCS apud MÉSZÁROS, 2013, p. 62).

Pode-se dizer que, ao menos nos campos filosófico, estético e ético, a mediação não somente conquistou reconhecimento mais amplo como alcançou inequívocos resultados. Dizemos "ao menos" porque, como a situação imediata colocava limites quase intransponíveis para a ação política - e, por conseguinte, para a própria reflexão política -, as conquistas teóricas de Lukács ocorreram sobretudo "naquelas obras em que a investigação pôde permanecer em um nível mais abstrato. Nessas obras, ele explora sistematicamente os intrincados problemas da mediação em seus aspectos multiformes como nenhum filósofo 0 fez na mesma época ou antes dele" (MÉSZÁROS, 2013, p. 63). Contraditoriamente, então, enquanto tais limites e sua confiança no desenvolvimento do socialismo na URSS forneceram um caráter abstrato a certos aspectos das reflexões políticas nas quais intentou elucidar as mediações superadoras dos dilemas ser e dever-ser - mantendo-se um abismo entre os problemas imediatos e as conquistas filosóficas de caráter universal -, ambos criaram uma situação que o permitiram "explorar o campo objetivamente dado de ação até seus limites extremos, criando assim uma obra que não é comparável com absolutamente nenhum empreendimento produzido no mundo soviético" (MÉSZÁROS, 2013, p. 67) - quiçá, em todo o mundo. Portanto, à sua maneira, os limites da realização do socialismo na URSS - e, de certo modo, a degeneração de sua construção - e a confiança - não desprovida de crítica - em sua correção fomentaram, ao mesmo tempo, a grandeza e a miséria das realizações de Lukács. E, diga-se, é justamente no tratamento lukacsiano da dialética da mediação e de suas conexões com a situação sociopolítica e ideológica desta produção que se encontra 0 aspecto mais elaborado do livro.

Quanto às insuficiências para a compreensão do tema, por ter sido publicado originalmente em 1971, ele praticamente não contempla os últimos e monumentais escritos do controverso filósofo. E, nessa questão, há que se constatar que, não apenas de maneira retrospectiva, mas também à luz das conclusões do próprio Mészáros "deve-se enfatizar que é impossível haver originalidade sem essa unidade - relativa, dialética - de pensamento no que se refere à sua estrutura geral" [...] 'ruptura total' não é o mesmo que 'mudança qualitativa' [...] A 'conversão total' é privilégio de uma segunda infância normal que deve suceder a uma amnésia completa - (MÉSZÁROS, 2013, p. 33-34), uma avaliação mais abrangente e detalhada da trajetória do longevo comunista deve 
necessariamente incluí-las. Eis aí uma tarefa (necessária) para a qual esse opúsculo é, como ponto de partida, de grande valia.

Com fins de esclarecimento, cabe ainda assinalar que, embora escritos numa perspectiva um pouco distinta, o derradeiro acerto de contas de Mészáros com os limites da dialética da mediação em Lukács pode ser encontrado em alguns capítulos de Para além do capital (MÉSZÁROS, 2002). Embora, nem mesmo aí, dada sua ênfase primordialmente política, Mészáros investigue 0 tratamento desta questão nas "ontologias".

Esses são, portanto, alguns aspectos analisados por Mészáros em $O$ conceito de dialética em Lukács, que ainda contém dois apêndices, com destaque para 0 artigo "György Lukács e a filosofia do 'tertium datur', uma cronologia resumida e uma ampla bibliografia do e sobre o filósofo.

\section{REFERÊNCIAS}

LUKÁCS, György. El joven Hegel y los problemas de la sociedade capitalista. México: Grijalbo, 1963.

LUKÁCS, György. História e consciência de classe. São Paulo: Martins Fontes, 2003.

LUKÁCS, György. Introdução a uma estética marxista. 2. ed. Rio de Janeiro: Civilização Brasileira, 1970.

LUKÁCS, György. Moses Hess y los problemas de la dialéctica idealista. In: . Táctica e ética: escritos tempranos (1919-1929). Buenos Aires: Ediciones El Cielo Por Asalto, 2005.

MÉSZÁROS, István. O conceito de dialética em Lukács. São Paulo: Boitempo, 2013.

MÉSZÁROS, István. Para além do capital. São Paulo: Boitempo, 2002. 